\title{
A concise overview of national nutrition action plans in the European Union Member States
}

\author{
Carl Lachat ${ }^{1,2}$, John Van Camp ${ }^{1, *}$, Stefaan De Henauw ${ }^{3,4}$, Christophe Matthys ${ }^{3}$, \\ Yvan Larondelle ${ }^{5}$, Anne-Marie Remaut-De Winter ${ }^{1}$ and Patrick Kolsteren ${ }^{1,2}$ \\ 'Department of Food Technology and Nutrition, Faculty of Agricultural and Applied Biological Sciences, Ghent \\ University, Coupure links 653, B-9000 Ghent, Belgium: ${ }^{2}$ Nutrition Unit, Department of Public Health, Prince Leopold \\ Institute of Tropical Medicine, Antwerp, Belgium: ${ }^{3}$ Department of Public Health, Faculty of Medicine and Health \\ Sciences, Ghent University, Ghent, Belgium: ${ }^{4}$ Department of Health Sciences - Vesalius, Hogeschool Gent, Ghent, \\ Belgium: ${ }^{5}$ Unité de Biochimie de la Nutrition, Faculté d'Ingénierie Biologique, Agronomique et Environnementale, \\ Université Catholique de Louvain, Louvain-la-Neuve, Belgium
}

\section{Submitted 14 July 2004: Accepted 25 October 2004}

\begin{abstract}
Objective: This study presents an overview of national nutrition action plans in the member states of the European Union (EU), before its enlargement in 2004. In addition, their compliance with key recommendations of the World Health Organization, as documented in the First Action Plan for Food and Nutrition Policy and the Global Strategy on Diet, Physical Activity and Health, has tentatively been evaluated on the basis of the policy documents published.

Design: Literature review of publicly available policy national plans on nutrition and physical activity.

Setting: Member states of the EU before enlargement in May 2004.

Results: The development of national nutrition action plans is gaining momentum. Six of the 15 EU member states - namely, Sweden, Finland, Denmark, France, The Netherlands and the UK - have an operational nutrition policy and four of them have published an elaborated description of their nutrition policy in English. By the end of 2004 , another four countries are expected to have their plan finalised. The available nutrition action plans generally seem to comply with international recommendations, although large variations are observed between the member states in terms of terminology, nutritional recommendations, institutional framework, nutritional scope, social groups targeted and monitoring and evaluation structures.

Conclusions: Although the importance of nutritional surveillance, a comprehensive approach to nutritional problems and stakeholder involvement is recognised by the action plans, the justification for it is vaguely described. This paper advocates for proper evaluation and documentation of interventions in public health nutrition and nutrition policies.
\end{abstract}

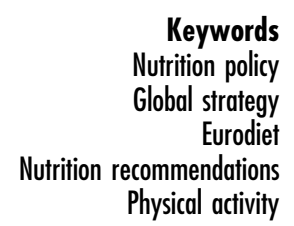

Keywords

Nutrition policy

Eurodiet

Physical activity
Obesity has reached epidemiological proportions worldwide and although the map is still being drawn, convincing evidence indicates that obesity and overweight are widespread in Europe ${ }^{1}$. The burden of diseases attributable to nutrition is substantial ${ }^{2-4}$. Diet and physical inactivity have been estimated to be implicated in onethird of cardiovascular diseases, in 30-40\% of certain types of cancer and in the pan-European epidemic of overweight and obesity ${ }^{5}$. The importance of diet and nutrition in the development of diseases such as diabetes ${ }^{6}$, obesity ${ }^{7}$, cardiovascular diseases ${ }^{8}$ and certain types of cancer ${ }^{9}$ is generally well understood, and physical inactivity as a determinant of obesity has received increased attention ${ }^{10}$. While the aetiology of non-communicable diseases is being unravelled, estimations for childhood obesity ${ }^{11}$ and nutritional status of the total population in some European countries are alarming ${ }^{1}$.

The apparent nutritional problems call for political action. The 1992 International Conference on Nutrition in Rome provided a major impetus in political commitment. The final report encouraged participating countries to develop comprehensive national nutrition policies ${ }^{12}$. In 2000, the Member States of the World Health Organization (WHO) Regional Office for Europe agreed to implement the guidelines proposed in the First Action Plan for Food and Nutrition Policy in the period 2000-2005 $5^{13-15}$. More recently, international political commitment to public health nutrition culminated in the WHO Global Strategy 
on Diet, Physical Activity and Health (hereafter called the Global Strategy). The objective of the strategy is to provide a basis for concerted action to prevent non-communicable diseases ${ }^{16}$. Also at the level of the European Union (EU), public health nutrition policy is taking shape. The Amsterdam Treaty of 1997 aimed to safeguard public health in the decision-making process of the $\mathrm{EU}^{17}$. In the years that followed, public health nutrition crystallised during the French presidency into the EU Resolution on Health and Nutrition of $2000^{18}$. In the context of the new EU public health programme, several research programmes have been funded to provide an evidence base for a European nutrition policy. A milestone in terms of European nutritional recommendations are the conclusions of the pan-European study on Nutrition and Diet for Healthy Lifestyles in Europe (Eurodiet) in $2000^{5}$. The report justifies the need for a strong European dimension to support the development of nutrition action plans in the EU member states. A series of concerted activities under the broad umbrellas of 'health monitoring' and 'health promotion' programmes were aimed at harmonising public health monitoring and surveillance across Europe. One of these initiatives, the Nutrition and Physical Activity Network (NPAN), has been established as a discussion forum and advisory body for public health nutrition in the European Public Health Programme for $2003-2008^{19}$

In 1998, Milio and Helsing carried out an in-depth analysis of the food policies in Europe $^{20}$. Given the scarcity of national nutrition policies, the study drew largely on the experiences in Scandinavian countries. More recently, WHO compared the different food and nutrition strategies in place in WHO European Member States $^{21}$. The latter study is based on a survey of key government bodies using standardised questionnaires. The report is a state-of-affairs on available nutrition policies and data in 1998-1999 and enumerates what has been done in each of the WHO member states ${ }^{21}$.

The current international evolutions, however, call for an updated and in-depth overview of the progress made in terms of national nutrition policies in the EU. The present study describes what has been done so far in terms of nutrition policy at national level in response to the international recommendations. The background idea of the study was to assist the initiative of the Belgian food industry to play a proactive role in the development of a Belgian nutrition action plan. Generally, by sharing multiple experiences, it is hoped that this study will serve as input or incentive for other initiatives in countries that are developing or adjusting a plan or policy.

\section{Design}

One of the aims of NPAN is to share experiences in national nutrition, physical activity and obesity action plans. As it comprises representatives from key authorities in the field of nutrition, physical activity and public health in the respective member states ${ }^{22}$, this existing network provided a logical starting point for data collection. All members were asked by email if a national nutrition plan existed in their country, and if not, at what stage of development it was in. The next step was to enquire if such a plan has been published in English, French or Dutch and how a copy of the document could be obtained. The contact persons were emailed and called by telephone until point of redundancy. Data collection was completed using personal contacts, information services of governmental websites and a general search in databases, journals and the World Wide Web. All literature and action plans available were reviewed during the spring of 2004.

By and large, the present study is a literature review of nutrition action plans in the 15 member states of the EU on the eve of enlargement in May 2004. The First Action Plan for Food and Nutrition Policy, the Global Strategy and the conclusions of the Eurodiet project have a number of policy recommendations in common and are subjected to this review. In the present paper, the following topics are consecutively assessed and discussed.

\section{Availability and accessibility of a national nutrition and physical activity plan}

The concept of a Food and Nutrition Action Plan was outlined by WHO as: 'A plan which shows how to develop and implement food and nutrition policy'. In this context, food and nutrition policy refers to 'An umbrella term used to incorporate public health concerns into food policy ${ }^{, 15}$. The availability and accessibility of such national nutrition action plans was evaluated.

\section{Stakebolder involvement, comprebensiveness and settings for nutrition promotion}

Involvement and mobilisation of private industry in national nutrition policy has been an issue of debate and was stressed by $\mathrm{WHO}^{15,16}$ as a promising approach for public health ${ }^{23}$. Effective intersectoral action is an overall objective for a food and nutrition policy ${ }^{5,15}$. This study tentatively considered how the national plans relate to the WHO recommendations in terms of the stakeholders identified, description of their role and comprehensiveness. Additionally, the role of the consumer was appraised since the individual is increasingly rendered responsible for his/her health provided a supportive environment for an optimal lifestyle is created ${ }^{16}$. Eating outside the home has been associated with higher intakes of dietary fat and overweight $^{24-29}$. The catering sector is therefore recognised by WHO as a potentially important actor for health promotion $^{6,30}$. Health-promoting activities are typically deployed in some specific settings such as the workplace and schools ${ }^{1,16}$. The different settings and initiatives that target specific actors described in the policy documents were appraised. 


\section{Nutritional and physical activity recommendations for the population}

Although the resolution concerning the Global Strategy was adopted a few years after the publication of most policy documents reviewed, the present study tentatively examines to what extent the national recommendations were covered by it.

\section{Institutional framework and financial resources}

Both $\mathrm{WHO}^{15,16}$ and the Eurodiet report ${ }^{5}$ stress the need for coherence in a food and nutrition policy. Such coherence, however, requires a supportive institutional framework with co-ordinating structures ${ }^{21}$. The present study briefly assessed the institutional framework and identified the principal bodies responsible for the nutrition plan, including the budget allocated for its implementation.

\section{Reduction of social inequalities}

Several studies have shown differences in nutritional status among socially vulnerable groups and the poorer layers of society ${ }^{5,31,32}$. Strategies in the different countries that promote social equity with regard to health and nutrition were evaluated.

\section{Nutritional surveillance}

Both $\mathrm{WHO}^{15,16}$ and the Eurodiet project ${ }^{5}$ underline the need to monitor and evaluate the implementation of a nutrition action plan. The mechanisms for nutritional surveillance as described in the documents were reviewed.

\section{Results}

\section{Availability and accessibility of a national nutrition and physical activity plan}

From the minutes of NPAN it could be deduced that Belgium and Portugal have no operational plan. The policy documents from The Netherlands, Denmark and France were easily obtained from governmental websites. The NPAN members of the remaining 10 countries were subsequently contacted. Only two members of the network (Germany and Finland) did not reply. The information from these countries was obtained from the information services of the ministries in charge.

In total, six countries out of the 15 reported to have an operational national nutrition plan (Table 1). Roughly estimated, these countries represent $69 \%$ of the population of the EU at the time of the study. The countries with an operational plan are Sweden ${ }^{33}$, Finland ${ }^{34}$, Denmark ${ }^{35}$, France $^{36}$, The Netherlands ${ }^{37}$ and the $\mathrm{UK}^{38}$. Five countries - namely, Sweden, Italy, Ireland, Greece and Spain reported to be in the process of developing a plan. The Swedish plan for 1999-2004 is phasing out in 2004 and a new one is in preparation. All but the Swedish plan for 1999-2004 can be accessed publicly and consulted on the World Wide Web. For Finland, only a concise 4-page summary of the plan is available in English. All but The Netherlands have published an English version or summary of their nutrition policy. Hence, only three countries (France, Denmark and UK) have made an elaborated English version electronically available. A list of URLs to policy documents is included in the Appendix. At the time of this study, the Southern European region had

Table 1 Status of national action plans for nutrition in the member states of the European Union

\begin{tabular}{|c|c|c|c|c|}
\hline & Country & Status & Title and year & Source \\
\hline 1 & UK & Operational & $\begin{array}{l}\text { Nutrition strategic framework: proposed } \\
\text { action plan, } 2001\end{array}$ & Food Standards Agency \\
\hline 2 & The Netherlands & Operational & $\begin{array}{l}\text { Longer and healthy life: also a matter of } \\
\text { healthy conduct, } 2003\end{array}$ & $\begin{array}{l}\text { Ministry of Health, Welfare } \\
\text { and Sports }\end{array}$ \\
\hline 3 & Finland & Operational & $\begin{array}{l}\text { Summary of the action programme for implementing } \\
\text { national nutrition recommendations, } 2003\end{array}$ & $\begin{array}{l}\text { National Nutrition Council of } \\
\text { Finland }\end{array}$ \\
\hline 4 & Denmark & Operational & $\begin{array}{l}\text { Healthy throughout life: targets and strategies for } \\
\text { public health policy of the Government of } \\
\text { Denmark } 2002-2010,2003\end{array}$ & National Board of Health \\
\hline 5 & France & Operational & $\begin{array}{l}\text { National nutritional health programme, } \\
2001-2005\end{array}$ & $\begin{array}{l}\text { Secretary of State for } \\
\text { Health and Disabilities }\end{array}$ \\
\hline 6 & Sweden* & $\begin{array}{l}\text { Operational/ } \\
\text { in preparation }\end{array}$ & Aims and strategies for nutrition 1999-2004 & $\begin{array}{l}\text { National Institute of Public } \\
\text { Health and Swedish National } \\
\text { Food Administration }\end{array}$ \\
\hline 7 & Italy & In preparation & - & - \\
\hline 8 & Ireland & In preparation & - & - \\
\hline 9 & Greece & In preparation & - & - \\
\hline 10 & Spain & In preparation & - & - \\
\hline 11 & Belgium & No plan & - & - \\
\hline 12 & Germany & No plan & - & - \\
\hline 13 & Austria & No plan & - & - \\
\hline 14 & Luxembourg & No plan & - & - \\
\hline 15 & Portugal & No plan & - & - \\
\hline
\end{tabular}

- , not relevant.

* The Swedish plan for 1999-2004 is phasing out and a new plan for 2005 is under preparation. 
no country with an ongoing national programme for nutrition. In contrast, the member states of the Scandinavian region are well represented, with half of the countries having an effective action plan.

The terminology used to label the plans differs remarkably between the countries (Table 1). The nutrition plan in both Finland and France is presented as a programme $e^{34,36}$. Denmark works with a health policy ${ }^{35}$. The Swedish plan is presented as a list of 11 aims and strategies $^{33}$. In The Netherlands, the national plan is an annex to a parliamentary bill ${ }^{37}$. The policy document in the UK serves as a strategic framework for the development of separate plans in the nations of the $\mathrm{UK}^{38}$.

Nutrition is clearly not the sole determinant of health ${ }^{30}$. Consequently, with the exception of the UK, all nutrition plans underline being part of a national public health plan. France, Sweden and Finland have developed a plan for nutrition complementary to their public health plan. Denmark and The Netherlands have published a comprehensive health plan in which nutrition activities are incorporated. In addition to its health plan, Denmark has published a separate national action plan for obesity ${ }^{39}$.

\section{Stakeholder involvement, comprebensiveness and settings for nutrition promotion}

All nutrition plans in this study acknowledge the importance of a multidisciplinary approach and promote stakeholder involvement at some point. Table 2 summarises the stakeholders identified in the different nutrition plans. The stakeholders mobilised were firstly the governmental organisations. Other typical stakeholders are consumer organisations, research institutions, the private sector and schools. Most of the plans, however, do not elaborate on their specific role and strategies that will be used to mobilise the stakeholders.

The Dutch plan explicitly stresses the individual responsibility of the consumer for his/her health and nutritional behaviour but immediately draws attention to the collective responsibility. The plan in the UK places the consumer in a central position as the final beneficiary of the process, but does not elaborate on responsibilities. Although the Danish plan recognises the responsibility of the consumer, the principle maintained throughout the policy is that of collective responsibility. France emphasises the freedom of food choice for the consumer in the process of determination of his/her health but makes no allusions to responsibilities. The Swedish and Finnish plans do not elaborate on these issues.

Most nutrition plans acknowledge the importance of involving the private sector and identify various actors here (Table 3). The Danish plan proposes flexible partnerships to implement the programme and lists for each objective how the different stakeholders can contribute ${ }^{35}$. One of the central aims of the Swedish plan is to promote dialogue with the food industry ${ }^{33}$. Further initiatives were taken to identify and mobilise stakeholders for different activities in development of the plan for $2005^{40}$. In this context, the French plan incorporates specific activities to inform the food industry on how their commercial message ought to comply with national guidelines ${ }^{36}$. The Dutch plan promotes a self-regulation mechanism and encourages the entire commercial sector to participate in the activities. The food industry is particularly stimulated to lower the fat content and improve the fatty acid composition of their products. The government would only intervene with appropriate measures when self-regulation fails ${ }^{37,41}$. In the UK, specific structures have been put in place to ensure the dialogue with the food industry ${ }^{38,42}$. In line with the WHO recommendations, the various nutrition plans have developed guidelines to ensure the nutritional quality of meals provided outside the home. Specific strategies are formulated for this in all national nutrition plans. The UK, for instance, has developed and evaluated 'Catering for health' guidelines ${ }^{38}$.

All countries acknowledge the importance of schools in their nutritional policy and have developed appropriate

Table 2 Overview of stakeholders identified by the policy documents for nutrition and physical activity in operational national nutrition action plans

\begin{tabular}{|c|c|c|}
\hline & Principal co-ordinating bodies & Other stakeholders identified in the policy document \\
\hline Denmark & National Board of Health & $\begin{array}{l}\text { Individuals, families, communities, social networks, educational sector, } \\
\text { regions, voluntary organisations (e.g. sports clubs, parent committees), } \\
\text { private sector, research institutions }\end{array}$ \\
\hline Finland & $\begin{array}{l}\text { National Nutrition Council and } \\
\text { National Public Health Institute }\end{array}$ & $\begin{array}{l}\text { Food industry, consumer organisations, trade and agriculture } \\
\text { organisations, child-care centres, schools, social and } \\
\text { health services, army, research institutions }\end{array}$ \\
\hline Sweden & $\begin{array}{l}\text { National Institute of Public Health and } \\
\text { National Food Administration }\end{array}$ & $\begin{array}{l}\text { Food producers, retail and distribution, schools and mass catering, } \\
\text { consumer organisations, national board for education }\end{array}$ \\
\hline France & Secretary of State for Health and Disabilities & $\begin{array}{l}\text { Research, national health service, consumer organisations, } \\
\text { schools, private sector }\end{array}$ \\
\hline Netherlands & $\begin{array}{l}\text { Ministry of Health, Welfare and Sports } \\
\text { and Ministry of Agriculture, Fisheries and } \\
\text { Food Quality }\end{array}$ & $\begin{array}{l}\text { Consumer organisations, communities, schools, private sector, } \\
\text { health-care sector }\end{array}$ \\
\hline UK & $\begin{array}{l}\text { Food Standards Agency and } \\
\text { Department of Health }\end{array}$ & $\begin{array}{l}\text { Consumer organisations, voluntary organisations, schools, } \\
\text { food industry and retail sector, agricultural organisations }\end{array}$ \\
\hline
\end{tabular}


Table 3 Overview of stakeholders from the private sector mentioned in the policy documents for nutrition and physical activity

\begin{tabular}{|c|c|c|c|c|c|c|}
\hline & Denmark & Finland & Sweden & France & The Netherlands & UK \\
\hline Food industry & 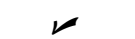 & 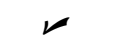 & 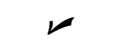 & 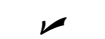 & 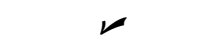 & レ \\
\hline Retailers & 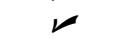 & $x$ & 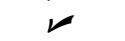 & $\nu$ & $x$ & $\nu$ \\
\hline Catering companies & レ & 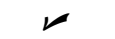 & 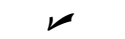 & $\nu$ & 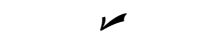 & $\nu$ \\
\hline Sports goods manufacturers & レ & $x$ & 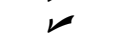 & $x$ & $\swarrow$ & $x$ \\
\hline Advertising and recreation businesses & レ & $\times$ & $\nu$ & $x$ & $\nu$ & $x$ \\
\hline Insurance and banking groups & $x$ & $\times$ & $x$ & $\nu$ & 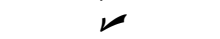 & $x$ \\
\hline Pharmaceutical companies & $\times$ & $x$ & $x$ & レ & $\nu$ & $x$ \\
\hline Media & $x$ & $\nu$ & $x$ & レ & 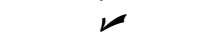 & $x$ \\
\hline
\end{tabular}

$\checkmark-$ mentioned explicitly in the policy document; $x$ - not mentioned explicitly in the policy document.

activities (Table 2). Health promotion in the workplace seems to be less apparent, however, and is not mentioned explicitly in action plans in France and Finland. Remarkable is the Danish initiative to incorporate setting-sensitive indicators in their monitoring and evaluation programme, although research in this field is currently in progress ${ }^{35}$.

\section{Nutritional and physical activity recommendations for the population}

Most nutrition policies largely adopt the WHO nutritional recommendations from the Global Strategy. Table 4 summarises some essential WHO nutritional recommendations and compares them with those listed in the action plans in this study. Additionally, some other specific national recommendations that were not included in the Global Strategy are tabulated. Recommendations from the Global Strategy such as promotion of breast-feeding, fruits and vegetables, increased physical activity and the reduction of total fat and saturated fat are covered by most countries. Strategies that aim to limit intake of salt and simple sugars are less common, however. Large variations are observed between the countries for many of the additional recommendations that were not included in the Global Strategy.

The nutrition plans of France and The Netherlands give clear and quantified dietary recommendations for a specific timeframe. Some examples are 'Reduction of the prevalence of overweight and obesity by $20 \%$ ', 'Reduction of the consumption of alcohol by at least $20 \mathrm{~g}$ per day in the general population' (France) and 'The number of people with obesity or overweight should not increase' (The Netherlands). The Danish aims, though, are broad and focus on considerable changes rather than on a quantified reduction, e.g. 'The number of heavy consumers of alcohol should decrease significantly' or 'Alcohol consumption amongst youngsters should decrease and should be absent in children'. The Swedish plan does not pinpoint numbers and remains descriptive on the nutritional objectives. The plan for the UK is a general blueprint for the elaboration of specific activities in the different nations of the UK. It leaves quantification to the devolved plans and results of ongoing scientific research.

Table 4 Overview of some selected recommendations covered by the national action plans

National recommendations covered by the Global Strategy
Promotion of fruit and vegetable intakes
Reduction of total fat and saturated fat intakes
Reduction of consumption of simple sugars
Reduction of salt intake
Support of breast-feeding
lodisation of salt
Increase physical activity
Specific national recommendations not covered by the Global Strategy
Increase intake of complex carbohydrates and fibre
Promotion of iron intake among specific target groups
Increased intake of folic acid
Increased intake of vitamin D
Increased intake of calcium
Reduction of alcohol intake
Discouraging of smoking

$\checkmark$ - mentioned explicitly in the policy document; $x$ - not mentioned as such in the policy document.

* The Danish plan aims for an adequate intake of iodine through the diet. The plan does specify whether this will be done through the iodisation of salt ${ }^{35}$

† Only as reduction of simple sugars.

¥The policy document of Finland does not mention iodisation of salt. However, in Finland, salt has been iodised since $1949^{43}$

$\S$ Only as increased intake of fibre.

I Only at research level. 


\section{Institutional framework and financial resources}

Table 2 summarises the main governing bodies in the different countries as identified in the policy documents. A high degree of intersectoral co-operation is attained in Finland, where all stakeholders convene in the National Nutrition Council ${ }^{34,43}$, reflecting the Finnish endeavours to reach consensus at a high administrative level. In the UK, the nutrition policy is devolved to the nations ${ }^{42}$. The principal governing structures, the Food Standards Agency and the Department of Health, follow a similar decentralisation. The Nutrition Forum, an advisory body of the Department of Health, is the platform for the involvement of the other stakeholders ${ }^{44}$. The Dutch plan is largely executed and co-ordinated through the Ministry of Health, Welfare and Sports and the Ministry of Agriculture, Nature and Food Quality. A specific organ, the Netherlands Nutrition Centre, is established to furnish information for all stakeholders ${ }^{41}$. In Scandinavian countries, specific institutions such as the National Institutes of Public Health (e.g. Sweden and Finland) have been established under the ministries in charge. In Denmark, national nutrition action is centralised in the National Board of Health ${ }^{35}$.

Only the plan from The Netherlands describes a fairly detailed budget breakdown. In the strategic framework of the UK, a summary is documented. The other countries do not elaborate on the financial resources of the plan.

\section{Reduction of social inequalities}

All operational nutrition plans have strategies in place to reduce social disparities (Table 3). Long-established vulnerable groups in society such as pregnant women, children and the elderly are included in all active policies. Specific target groups, however, vary considerably between countries. The nutrition policy document in The Netherlands states that social differences are persisting and that additional efforts are required to reduce social inequalities ${ }^{37}$. The Dutch nutrition policy has a specific component aimed at disadvantaged districts in large cities. One of the central aims in the Swedish plan is to promote the involvement of disabled people in their role as food consumers. Social equity in health is one of the central themes in the Danish plan, which aims to establish a community network that provides social support for specific target groups such as alcoholics and the elderly. Relevant indicators are included in the nutritional surveillance programme. The French programme envisages nutritional care for patients and people on restrictive diets. The UK embarks on specific activities and studies to address the challenges that low-income groups face in achieving optimal lifestyles.

\section{Nutritional surveillance}

Evaluation activities seem to vary considerably between the different action plans. All plans but the Dutch refer to nutritional surveillance activities. Noteworthy is the Danish indicator programme. It is a detailed list of indicators that will be followed with a description of their trends and sources. The indicator programme is revised continuously and is accompanied by a Danish website to disseminate the main results and trends. The indicators are based on scientific studies or international guidelines and are developed for different settings of health promotion (roads, workplace) and vulnerable groups of society. They are divided into two main groups: key indicators that relate to the general objectives and specific indicators that envisage monitoring the specific objectives. Other countries are less explicit for their monitoring and evaluation system and refer to the responsible institutions for further information. The Dutch plan aims to monitor the process rather than its impact through performance indicators, as developed by the health project from the Organisation for Economic Co-operation and Development. Dissemination and restitution of the monitoring and evaluation results to the stakeholders is poorly described and seems limited to regular standardised reports produced by the responsible institutions. Additionally, none of the countries except Denmark documents the theoretical foundations and development process of their nutritional surveillance system. Systematic evaluations of previous national experiences with a nutritional surveillance were not found.

\section{Discussion}

Public health nutrition is in a state of transition in the EU. The guidelines in the Global Strategy now provide a solid basis for action and appeal to political initiatives. Several EU Member States have responded to the call of WHO and have developed and implemented an action plan. Their response, however, has been coloured by the local context of the countries and considerable variations emerge in the policy documents. The present paper identifies a seemingly large variation in nutritional scope and recommendations, stakeholder involvement, nutritional surveillance and social approach within the nutritional action plans. These findings may be attributable to the fact that not all plans have been elaborated in detail and some are presented as a general policy rather than a practical action plan. Some countries have published summarised guidelines while others have provided details.

The methodological approach in the present paper calls for some caution when interpreting the results. The scope of this study is limited to nutrition policies at national level only. In Germany, for instance, the Federal Ministry of Consumer Protection, Food and Agriculture reported that only a plan for food monitoring is being prepared but no plan for nutrition. In addition, regional initiatives, which may be (and indeed are) present in a large number of countries, were excluded. As described earlier, the essential idea of a food and nutrition action plan is to provide a pragmatic outline for the implementation of a food and nutrition policy. The objective of establishing 
national nutrition recommendations is essentially different in this respect. Although many countries have made considerable progress in this field, this was not reviewed as such in the present study.

A second point of attention is that this study appraised the sheer content of the policy documents as originally published. The policy itself, however, may have undergone changes during its course, for example due to the emergence of new nutritional challenges, new scientific evidence or changes in the political landscape of the country. A nutrition plan may furthermore not be published for operational purposes but merely to inform the public. The policy documents considered in this study, however, are often the sole reference for stakeholders. The perspective of this study could therefore be interpreted as that of the stakeholder and third parties concerned.

\section{Availability and accessibility of a national nutrition and physical activity plan}

A considerable number of countries are in the process of developing their plan and the beating heart of public health nutrition policy is extending its scope gradually from the Scandinavian region to the whole of Europe. Scandinavia traditionally has had a pioneering role, with a long history of national nutrition recommendations. The Swedish plan for 1999-2004 is based on their National Plan of Action for Nutrition that dates back to $1995^{33}$. Combined Nordic nutrition recommendations date back to $1968^{45,46}$. Political awareness in the region towards public health nutrition has increased gradually over time, in particular with the evident successes of the North Karelia project, a community-based prevention project for cardiovascular diseases in Finland ${ }^{47}$. Although Norway was not considered in this study, it is worth noting that it has been very active in Europe with an inspiring comprehensive nutrition policy since $1975^{21,46,48}$. Although the 10 countries that joined the EU in May 2004 were also not considered, it is equally important to point to the progress made in the Baltic Region. Two workshops were held in 2001 and 2002 at which Estonia, Latvia and Lithuania presented the final draft of their national action plan. In a WHO study, all three countries reported to have implemented nutrition strategies in 1994/ $1995^{21}$. Since the present study did not address these countries, it is not clear whether these policies were still operational at the time of writing.

\section{Stakebolder involvement, comprebensiveness and settings for nutrition promotion}

Very little information seems to be available on how different actors contributed to the development of the plan. It therefore seems that stakeholder mobilisation is largely restricted to the implementation phase. Worth mentioning in this context, however, is the public consultation process for the nutrition plan of Wales. A series of consultative workshops was held to reach global consensus, mobilise stakeholders and create a sense of ownership during the development of the Welsh Action Plan. In 2002, two months were allocated for a written consultation of all stakeholders involved ${ }^{49}$. All consultation documents and suggestions are publicly available through websites. The process yielded valuable responses that were taken into account during the preparation of the final policy document. The overall process was generally considered relevant and timely ${ }^{50}$.

Noteworthy is the fact that comprehensive concepts appear to be generally adopted by all national nutrition policies. Additionally, all the action plans recognise the importance of mobilising different actors and include strategies to involve them in the implementation phase of the policies. Nevertheless, the lack of documentation of the planning phase gives the impression of a top-down approach where actors are involved only in the execution phase. This may be too late. Previous experiences have highlighted the importance of involving actors as stakeholders during the development stage of nutrition policies, as far as back the planning ${ }^{50}$. Some actors may not contribute if their objectives are at stake. Mobilisation of the stakeholders and identification of their needs in earlier phases of policy development therefore seems a prerequisite for successful intersectoral action.

\section{Nutritional and physical activity recommendations for the population}

Some of the plans are comprehensive and tackle most of the nutritional recommendations of the Global Strategy and Eurodiet, while others are less explicit or leave out some health determinants. There is large variation in how nutritional objectives and dietary recommendations are documented, in particular for those which are not included in the Global Strategy. As mentioned, some policy documents, like that from Sweden, do not elaborate on specific nutrients or respective dietary recommendations and remain descriptive. The Finnish summary is too concise to provide a clear idea of the nutritional scope.

\section{Institutional framework and financial resources}

The institutional framework is logically tailored to the local administrative context of the member states. Given the diversity in the EU, considerable variations are therefore observed in policy-supporting structures. Only two countries provided insight into the budget allocated to implement the national nutrition plan.

\section{Reduction of social inequalities}

Though traditional vulnerable groups such as children and pregnant women are embraced by all nutrition policies, large variations are observed for other social strata. The rationale and evidence base behind this remain generally poorly described.

\section{Nutritional surveillance}

Monitoring, evaluation and nutritional surveillance are generally called for, but not well defined. All nutrition 
action plans in this study underline the importance of surveillance activities but only Denmark presents a clear outline of their programme. Although speculative however, the intensive EU supranational activities to harmonise public health monitoring might have a temporary counterproductive effect in individual member states to the extent that responsible authorities would temporise the launch of new initiatives in the attendance of a structured and guiding European framework. Apart from the Danish policy, it remains unclear whether monitoring and evaluation is done through epidemiological surveillance or nutrition surveillance. A prerequisite for nutritional surveillance is the need for information on the determinants of nutritional problems at hand ${ }^{51}$. The policy documents reviewed in this study remain vague on whether the determinants or the diseases are monitored. Theoretical foundations in this context are absent and not reported.

Finally, there seems to be a general dearth of properly reported evaluations of interventions in the field of public health nutrition policies. Documentation of what has worked and for what reason is vital, since it enables a cumulative build-up of experiences. Policies are generally developed from an 'evidence base' of conclusions, which are largely considered as 'proof' from experimental designs. In a strict sense, however, such 'proof' has intrinsic validity only to that particular experimental design. For health policies, Mackenbach and Bakker have argued that strategies to reduce social inequalities are largely intuitive approaches ${ }^{52}$. The findings above seem to indicate that this hypothesis applies for the nutritional policies as well. Given contemporary European nutritional challenges and large socio-economic variations within the EU, however, the need for solid conclusions that are useful for different settings is greater than ever.

\section{Acknowledgements}

The present paper is based on a literature study of available nutrition action that was sponsored by Fevia, the representative employers' organisation of the food industry in Belgium. The authors wish to thank Mr Chris Moris, Mr Johan Hallaert and Ms Siska Pottie for their valuable support, and Mrs Anne Opsomer for her constructive remarks during the preparation of the report.

\section{References}

1 World Health Organization (WHO). Obesity: Preventing and Managing the Global Epidemic. Report of a WHO Consultation. WHO Technical Report Series No. 894. Geneva: WHO, 2000.

2 Pomerleau J, McKee M, Lobstein T, Knai C. Burden of disease attributable to nutrition. Public Health Nutrition 2003; 6(5): 453-61.

3 Robertson A, Tirado C, Lobstein T, Jermini M, Knai C, Jensen $\mathrm{JH}$, et al., eds. Food and Health in Europe: A New Basis for Action. World Health Organization (WHO) Europe, Regional
Publications European Series No. 96. Copenhagen: WHO, 2004.

4 Kromhout D. Epidemiology of cardiovascular diseases in Europe. Public Health Nutrition 2001; 4(2B): 441-57.

5 Kafatos AG, Codrington CA. Eurodiet Core Report, Nutrition \& Diet for Healthy Lifestyles in Europe, Science \& Policy Implications. Crete: University of Crete, School of Medicine and European Commission DG Sanco, 2000.

6 Steyn NP, Mann J, Bennet PH, Temple N, Zimmel P, Tuomilehto J, et al. Diet, nutrition and the prevention of type 2 diabetes. Public Health Nutrition 2004; 7(1A): 147-65.

7 Swinburn BA, Caterson I, Seidell JC, James WPT. Diet, nutrition and the prevention of excess weight gain and obesity. Public Health Nutrition 2004; 7(1A): 123-46.

8 Reddy KS, Katan MB. Diet, nutrition and the prevention of hypertension and cardiovascular diseases. Public Health Nutrition 2004; 7(1A): 167-86.

9 Key YJ, Schatzkin A, Willett WC, Allen NE, Spencer EA, Travis RC. Diet, nutrition and the prevention of cancer. Public Health Nutrition 2004; 7(1A): 187-200.

10 Astrup A. Healthy lifestyle in Europe: prevention of obesity and type II diabetes by diet and physical inactivity. Public Health Nutrition 2001; 4(2B): 499-515.

11 Livingstone MBE. Childhood obesity in Europe: a growing concern. Public Health Nutrition 2001; 4(1A): 109-16.

12 Food and Agriculture Organization (FAO)/World Health Organization (WHO). International Conference on Nutrition, Final Report of the Conference. W/U9265/E. Rome: FAO/WHO, 1992.

13 World Health Organization (WHO) Regional Committee for Europe. The Impact of Food and Nutrition on Public Health, The Case for a Food and Nutrition Policy and an Action Plan for the European Region of WHO 2000-2005. WHO Regional Committee for Europe Resolution EUR/RC50/R8. Copenhagen: WHO, 2000.

14 World Health Organization (WHO) Regional Office for Europe. Progress Report on the First Action Plan for Food and Nutrition Policy in WHO European Region 2000-2005, Progress Report for the Period 2000-2005. Copenhagen: WHO, 2002.

15 World Health Organization (WHO). The First Action Plan for Food and Nutrition Policy, European Region 2000-2005. Nutrition and Food Security Programme Division of Technical Support and Strategic Development. Copenhagen: WHO, 2001.

16 World Health Organization (WHO). Global Strategy on Diet, Physical Activity and Health, Resolution of the Fifty-seventh World Health Assembly. WHA57.17. Geneva: WHO, 2004.

17 Treaty of Amsterdam amending the treaty on European Union, the treaties establishing the European communities and certain related acts 97c 340/01. Official Journal of the European Communities, 1997.

18 Council resolution of 14 December 2000 on health and nutrition 2001/C 20/01. Official Journal of the European Communities, 2001.

19 Nutrition and Physical Action Network, NPA members, European Commission, Health and Consumer Protection Directorate General, Directorate G, Public Health, G3 Health Promotion, Health Monitoring and Injury Prevention. Luxembourg: European Commission (not dated).

20 Milio N, Helsing E, eds. World Health Organization (WHO) European Food and Nutrition Policies in Action. WHO Europe, Regional Publications European Series No. 73. Copenhagen: WHO, 1998.

21 World Health Organization (WHO) Europe. Comparative Analysis of Food and Nutrition Policies in WHO European Member States, Full Report. Nutrition and Food Security Programme, WHO European Office for Europe. Copenhagen: WHO, 2003.

22 European Commission, Health and Consumer Protection 
Directorate General, Directorate G, Public Health, G3 Health Promotion, Health Monitoring and Injury Prevention. Nutrition Physical Activity Network, Mandate. Luxembourg. European Commission, 2003.

23 Buse K, Waxman A. Public-private health partnerships: a strategy for WHO. Bulletin of the World Health Organization 2001; 79(8): 748-54.

24 McCrory MA, Fuss PJ, Saltzman E, Roberts SB. Dietary determinants of energy intake and weight regulation in healthy adults. American Society for Nutritional Sciences 2000; 130: 276S-9S.

25 Binkley JK, Eales J, Jekanowski M. The relation between dietary change and rising US obesity. International Journal of Obesity and Related Metabolic Disorders 2000; 24(8): 1032-9.

26 Jeffery RW, French SA. Epidemic obesity in the United States: are fast foods and television viewing contributing? American Journal of Public Health 1998; 88(2): 277-80.

27 Clemens LH, Slawson DL, Klesges RC. The effect of eating out on quality of diet in premenopausal women. Journal of the American Dietetic Association 1999; 99(4): 442-4.

28 Kant AK, Graubard BI. Eating out in America, 1987-2000: trends and nutritional correlates. Preventive Medicine 2004; 38(2): 243-9.

29 Burns C, Jackson M, Gibbons C, Stoney RM. Foods prepared outside the home: association with selected nutrients and body mass index in adult Australians. Public Health Nutrition 2002; 5(3): 441-8.

30 World Health Organization (WHO). Diet, Nutrition and the Prevention of Chronic Diseases. Report of a Joint WHO/FAO Expert Consultation. WHO Technical Report Series No. 916. Geneva: WHO, 2003

31 Johnson-Down L, O'Loughlin J, Koski KG, Gray-Donald K. High prevalence of obesity in low income and multi-ethnic schoolchildren: a diet and physical activity assessment Journal of Nutrition 1997; 127(12): 2310-5.

32 Dowler E. Inequalities in diet and physical activity in Europe. Public Health Nutrition 2001; 4(2B): 701-9.

33 Swedish National Institute for Public Health, Swedish National Food Administration. Swedish National Aims and Strategies for Nutrition, 1999-2004. Uppsala: Livsmedelsverket, 2000.

34 National Nutrition Council Finland. Summary of the Action Programme for Implementing National Nutrition Recommendations. Helsinki: National Nutrition Council Finland, 2003.

35 Ministry of Interior and Health. Healthy throughout Life: The Targets and Strategies for Public Health Policy of the Government of Denmark 2002-2010. Copenhagen: Ministry of Interior and Health of Denmark, 2003.

36 Ministère de l'Emploi et de la Solidarité, Ministère délégué à la Santé. Programme National Nutrition-Santé PNNS 2001-2005. Paris: Ministère de l'Emploi et de la Solidarité, Ministère délégué à la Santé, 2001.
37 Ministerie van Volksgezondheid, Welzijn en Sport. Langer Gezond Leven, ook een Kwestie van Gezond Gedrag [Longer and Healthy Life: Also a Matter of Healthy Conduct]. POG/OGZ/2.424.450. Den Haag: Ministerie van Volksgezondheid, Welzijn en Sport, 2003

38 Food Standards Agency (FSA). Nutrition Strategic Framework: Proposed Action Plan. FSA 01/08/02. London: FSA, 2001.

39 Danish National Board of Health. National Action Plan against Obesity: Recommendations and Perspectives, Short Version. Copenhagen: Centre for Health Promotion and Prevention, 2003.

40 National Food Administration, National Institute of Public Health. A Basis for an Action Plan Concerning Healthy Eating Habits and Increased Physical Activity. Stockholm: National Food Administration, National Institute of Public Health, 2004.

41 Voedingscentrum website: www.voedingscentrum.nl Accessed 18 June 2004.

42 Food Standards Agency. Strategic Plan 2001-2006: Putting Consumers First. FSA/0020/0501. London: FSA, 2001.

43 Lahti-Koski M, ed. Nutrition in Finland. National Public Health Institute. Helsinki: Finnish National Nutrition Surveillance System (undated)

44 Nutrition Forum. Terms of Reference. NF 03/20. London: Nutrition Forum, 2002.

45 Prättälä R. Dietary changes in Finland, success stories and future challenges. Appetite 2003; 41: 245-9.

46 Kjaernes U. Food and nutrition policy of the Nordic countries: how have they been developed and what evidence substantiates the development of these policies? Proceedings of the Nutrition Society 2003; 62: 563-70.

47 Puska P. Successful prevention of non-communicable diseases: 25 year experience with North Karelia project in Finland. Public Health Medicine 2002; 4(1): 5-7.

48 Kjaernes U. Experiences with the Norwegian nutrition policy. Appetite 2003; 41: 251-7.

49 Food Standards Agency Wales, Welsh Assembly Government. Nutrition Strategy for Wales: Consultation Document. Cardiff: Food Standards Agency Wales, Welsh Assembly Government (not dated)

50 Food Standard Agency Wales, Welsh Assembly Government. Food and Well Being, Reducing Inequalities through a Nutrition Strategy for Wales. FSA/0724/1202. Cardiff: Food Standards Agency Wales, Welsh Assembly Government, 2003.

51 Maire B, Beghin I, Delpeuch F, Kolsteren P, Remaut-De Winter AM. La Surveillance Nutritionnelle: Une Approche Opérationnelle et Durable. Studies in Health Service Organisation and Policy No. 13. Antwerp: ITG Press, 1999.

52 Mackenbach JP, Bakker MJ. Tackling socioeconomic inequalities in health: analysis of European experiences. Lancet 2003; 362: 1409-14.

\section{Appendix - URLs of the national nutrition action plans reviewed in this study}

The Netherlands (Dutch only): http://www.minvws.nl/images/gevoed_tcm10-16 014.pdf

Denmark: http://www.sst.dk/Forebyggelse.aspx?lang $=$ en

Finland: http://www.mmm.fi/ravitsemusneuvottelukunta/Toim_ohj_ENG.htm

France: http://www.sante.gouv.fr/htm/pointsur/nutrition/1nbis.htm\#60

UK: http://www.foodstandards.gov.uk/multimedia/pdfs/NutritionStrategicFramework.pdf

Sweden: the policy document for Sweden is not publicly available in electronic format 